\title{
Monitoramento do nível do lençol freático do Rio Gualaxo do Norte, Mariana, MG
}

\author{
Glauber José Almeida Ramos ${ }^{1}$ \\ Herly Carlos Teixeira Dias ${ }^{1}$ \\ Vanessa Pataro Maffia ${ }^{1}$ \\ Wellington Avelar de Souza e Silva ${ }^{1}$ \\ ${ }^{1}$ Universidade Federal de Viçosa - UFV \\ Avenida Peter Henry Rolfs, s/n, Campus Universitário - 36570-000 -Viçosa - MG, Brasil \\ glauberramos.ufv@gmail.com \\ herly@ufv.br \\ vpmaffia@yahoo.com.br \\ tomavelar@hotmail.com
}

\begin{abstract}
The waterspout is one of the main components of water cycle and it guarantees the perennial rivers during dry seasons. The identification of the position of the sheets level and their variations can be made through the observation of the sheet made through piezometer wells. The main objective of this work was to monitor the level of the sheet of Rio Gualaxo of the North in Mariana Minas Gerais. The wells were perforated in three different blocks, three piezometers were perforated in each block, following a perpendicular transect to the left margin of the river. The manual perforation of the piezometer showed to be a viable alternative for the perforation of wells with to four meters of depth in loamy soils. The result obtained of the level sheet indicates that the sheet tends to accompany the relief of the land and the dynamics of the sheet at close points to the margin of the river is different from the most distant places
\end{abstract}

Palavras-chave: Monitoramento hidrológico, lençol freático, bacia hidrográfica.

\section{Introdução}

A importância da água na sociedade contemporânea encontra-se no foco não apenas de projetos de pesquisas como da administração pública. Apesar de ser essencial para qualquer atividade que o homem realize como a agricultura, atualmente problemas no mundo de escassez, poluição e distribuição estão comprometendo os recursos hídricos. Enquanto alguns países da África carecem de água, por outro lado, países como o Canadá, a Islândia e a Nova Zelândia estão "bem servidos" em relação a este recurso. Estes trabalhos buscam informações que possibilitem tanto o planejamento quanto para avaliar o impacto de mudanças nos usos da terra sobre os recursos hídricos.

As práticas de conservação das bacias hidrográficas têm o objetivo de proteger e restaurar a qualidade ambiental e consequientemente os ecossistemas aquáticos. Esta abordagem baseiase no fato de que muitos dos problemas de qualidade e quantidade de água são evitados ou resolvidos de maneira eficaz por meio de ações que focalizem a bacia hidrográfica como um todo, as atividades desenvolvidas em sua área de abrangência e os atores envolvidos.

No ciclo hidrológico o lençol freático é um dos principais componentes e garante a perenidade aos rios durante as estações secas. No ciclo hidrológico a água subterrânea e a superficial interagem continuamente. A identificação da posição do nível freático e suas variações podem ser feita através da observação do lençol efetuada por meio de poços piezômetros. Sem esquecer que as oscilações do lençol freático são afetadas também pelas variações climáticas periódicas.

Este trabalho trata da perfuração manual de poços piezômetros em local de difícil acesso, devido à declividade acentuada, e em solo argiloso. Além disso, apresenta dados e discute a dinâmica do lençol freático do Rio Gualaxo do Norte. O trabalho foi realizado na zona ripária, próxima à margem do rio, área que exerce função de manutenção da integridade da microbacia 


\section{Justificativas}

O lençol freático serve como suprimento de água para as atividades humanas, carrega sais, nutrientes e poluentes provindos de atividades agrícolas, industriais e minerações. Sendo assim é necessário um melhor conhecimento dos fatores ligados a ele, que possa gerar tecnologia para potencializar o uso sustentável dos recursos hídricos e minimizar os impactos sobre os mesmos. O levantamento das condições em que se encontra a água subterrânea, quanto à identificação da posição do nível freático e sua dinâmica, fornecem dados essenciais necessários para o desenvolvimento de modelos da dinâmica da água subterrânea e para projetar, implementar e monitorar a efetividade de programas de manejo e proteção das águas subterrânea.

Fica evidente a necessidade de estudos para melhor compreender a dinâmica de águas subterrâneas e o desenvolvimento de metodologias simples para o monitoramento do nível do lençol freático. Como ponto de partida do trabalho tem-se a obtenção de dados preliminares fundamentais que incluem estudos da topografia local mediante mapas topográficos com levantamento plani-altimétrico; dados hidrológicos quanto às fontes de águas superficiais que possam contribuir à recarga da água subterrânea; informações geológicas da área que permitam identificar camadas permeáveis e impermeáveis, regiões de recarga e descarga e tipos de aquíf́eros existente. O monitoramento do nível do lençol freático pode ser efetuado através de poços piezômetros, que geralmente são instalados por meio de máquinas. Estudos deste tipo

podem ser inviabilizados devido ao alto custo das operações e ao difícil acesso em terrenos de declividade acentuada.

Apesar disso, a perfuração manual se torna uma alternativa viável para reduzir os custos de monitoramento nas zonas ripárias nas quais a profundidade do poço não necessite ser elevada e onde as formações não apresentem rochas ou cascalhos grandes, que podem ocasionar danos na ponteira de cravação. As vantagens da perfuração manual é que os poços podem ser construídos em pouco tempo, com mão de obra reduzida, a um custo mínimo e em locais de difícil acesso.

\section{Metodologia}

\section{1. Área de estudo}

A bacia do rio Gualaxo do Norte é localizada na cidade de Mariana no estado de Minas Gerais e faz parte da bacia do rio Doce. O rio Gualaxo do Norte possui sua cabeceira em Mariana bem próxima à divisa com Ouro Preto e é afluente do Rio do Carmo. A área onde o experimento foi montado fica na região norte do município de Mariana e se encontra na

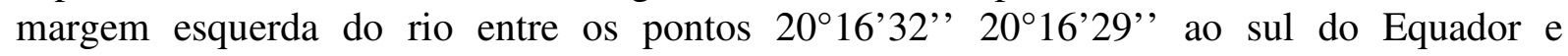
$43^{\circ} 26^{\prime} 14^{\prime}$ ' 4326'08', ao oeste de Greenwich (Figura 1).

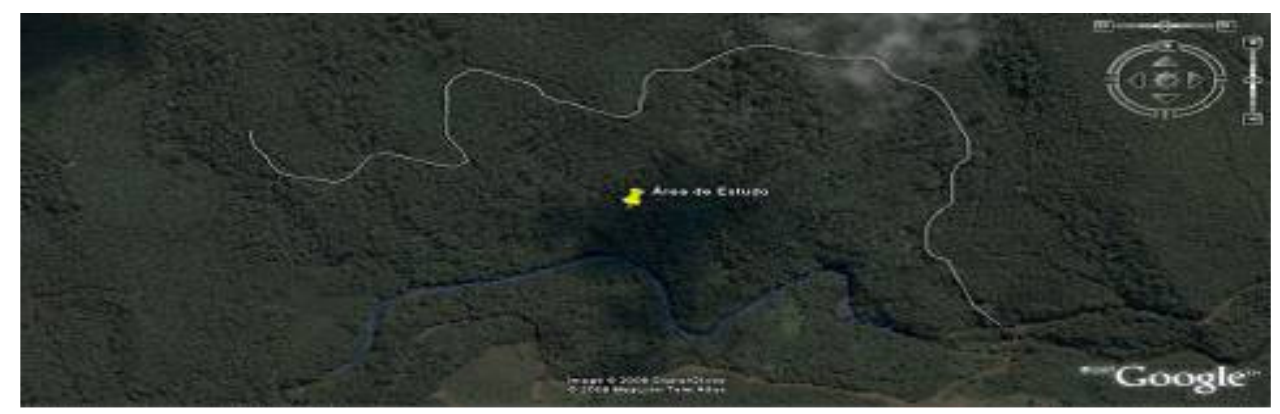

Figura 1: Margem esquerda do rio Gualaxo do Norte, onde foi realizado o estudo. 
O relevo é ondulado com altitudes superiores a 700m e declividades acentuadas. O clima da região é do tipo tropical de altitude, apresentando temperatura média anual de $19{ }^{\circ} \mathrm{C}$ e amplitude térmica anual entre $7^{\circ} \mathrm{C} \mathrm{e} 9^{\circ} \mathrm{C}$, as chuvas de verão são mais intensas devido à ação da massa tropical atlântica e no inverno as frentes frias originárias da massa polar atlântica podem provocar geadas. A cobertura vegetal do local pertence ao domínio da Mata Atlântica e apresenta boa preservação relacionada diretamente ao relevo mais acidentado, de acesso mais restrito e reduzido potencial agrícola de uso do solo. Apesar do potencial ambiental, é uma área ameaçada devido a uma falta de política municipal de conservação aliada a queimadas e constantes extrações ilegais de madeira e espécies vegetais por atividades clandestinas.

\subsection{Demarcação das parcelas}

O trabalho foi realizado em três blocos distintos, próximas à margem esquerda do rio. Em cada bloco foram perfurados três poços piezômetros com distâncias crescentes em relação a margem, seguindo um transecto. A distância entre os piezômetros foi de 20 metros. Cada piezômetro recebeu uma numeração de acordo com o bloco a qual pertenceu.

\subsection{Perfuração dos poços piezômetros}

\subsubsection{Equipamento}

A ferramenta utilizada para perfurar os poços piezômetros é composta por três componentes: uma manga externa, um preenchimento interno e um batedor (Figura 2). $\mathrm{O}$ preenchimento é uma barra de ferro maciça com uma polegada e meia de diâmetro e possui uma ponta de aço no final de uma polegada e meia de comprimento com um ângulo de $45^{\circ}$.A ponta da manga é desenhada para se ajustar com a ponta do preenchimento de tal forma que o conjunto manga-preenchimento forme uma ponta contínua. O lado oposto do preenchimento é equipado com um boné de 3 polegadas de diâmetro que impede que o preenchimento escape da manga, o boné provê uma superfície sólida para receber as pancadas pelo qual o conjunto manga-preenchimento possa ser simultaneamente introduzido ao solo. A manga externa possui dois furos de duas polegadas de diâmetro utilizados para introduzir uma barra de ferro que possa servir como uma alavanca na retirada da manga do solo após a perfuração do solo. O conjunto manga-preenchimento é introduzido no solo por um batedor deslizante.

$\mathrm{O}$ batedor consiste em um tubo metálico de quatro polegadas de diâmetro por cinqüenta e dois centímetros de comprimento, fechado em um dos lados que transmite o esforço para o conjunto manga-preenchimento que introduz no solo. Para a utilização do batedor há duas alças em ambos os lados do mesmo, formadas por tubos metálicos de $3 / 4$ de polegada de diâmetro. 


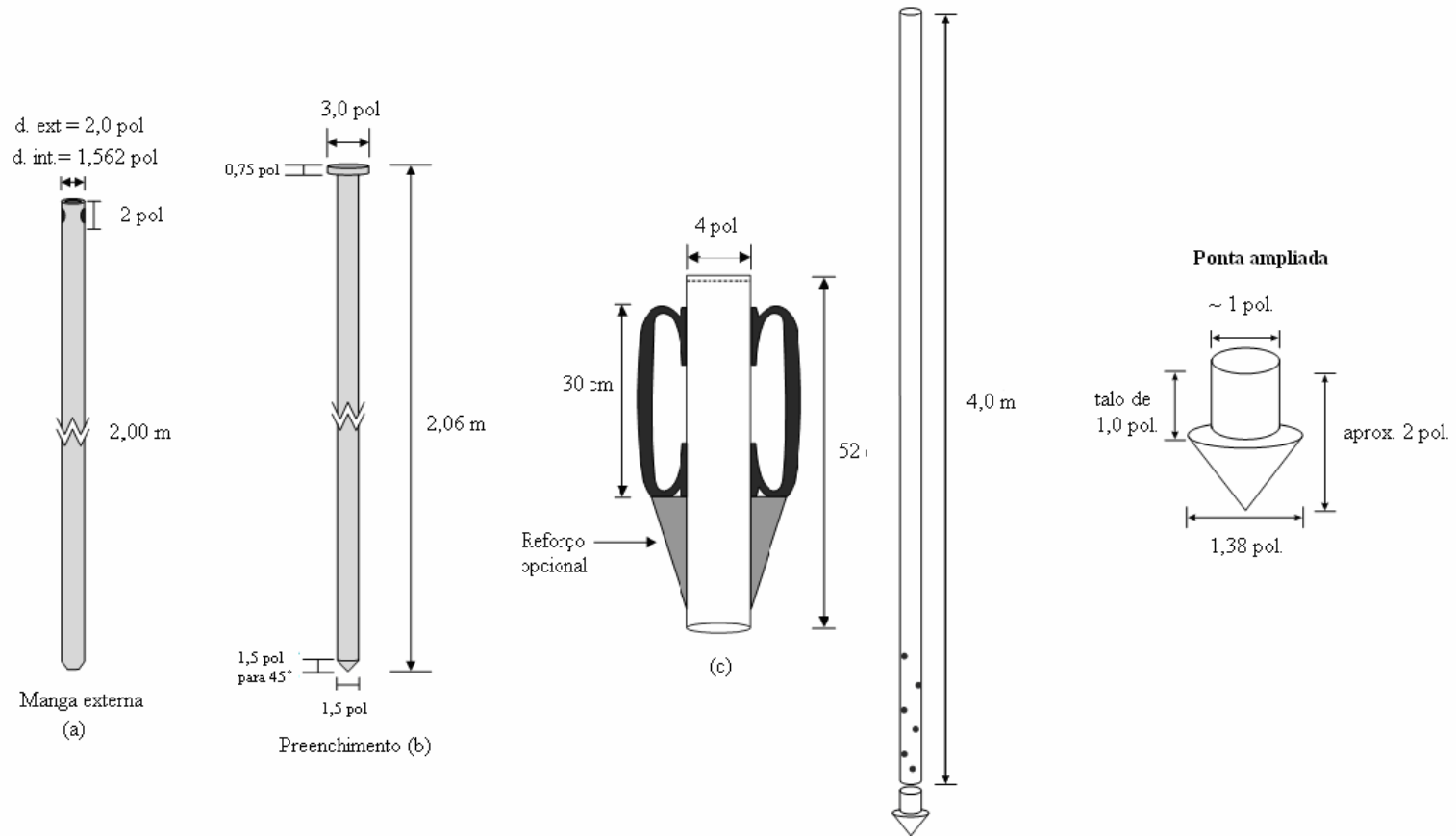

Figura 2: Componentes do equipamento utilizado para a perfuração manual de poços piezômetros: a) manga externa, b) preenchimento interno e c) batedor. Barra para perfuração de poços piezômetros de até quatro metros e detalhe da ponta de aço (fora de escala) (adaptado de BOHN, 2001).

Outro componente foi desenvolvido para perfurar dois metros adicionais para os locais onde o lençol é mais profundo, ele consiste de uma barra de ferro maciça de quatro metros de comprimento e uma polegada de diâmetro e também com uma ponta de aço soldada no final. Esta peça é encaixada no buraco após a perfuração e retirada do primeiro conjunto mangapreenchimento, ficando com uma metade do seu comprimento para dentro e a outra para fora do poço. $\mathrm{O}$ mesmo batedor pode ser utilizado para colocar o restante do cano.

\subsubsection{Procedimentos}

Com o preenchimento interno dentro da manga externa o final pontudo do conjunto é posicionado sobre o solo. O batedor desliza sobre o conjunto e transmite esforço por impacto, após perfurar cerca de metade do conjunto, pode-se virar o batedor de cabeça para baixo e bater com o fim fechado do batedor até que aproximadamente todo o conjunto fique introduzido no solo.

Para a perfuração de poços piezômetros de até dois metros, o preenchimento do conjunto inicial pode ser removido após a perfuração e substituído por um cano de PVC de vinte milímetros de diâmetro para formar o revestimento definitivo do poço. O diâmetro escolhido para o tubo foi de vinte milímetros por ser menor que o do conjunto manga-preenchimento, evitando assim dificuldades para penetrar no buraco além de ser compatível com a entrada da sonda do medidor de nível do lençol. Os últimos quinze a trinta centímetros do tubo de PVC são perfurados para permitir a entrada de água, o buraco perfurado tem diâmetro na ordem de $0,3 \mathrm{~cm}$. Para evitar o entupimento da abertura do cano por aglomerados do solo, uma tela de nylon foi colocada na parte externa da porção inferior do tubo de PVC. Após inserir o tubo de PVC a manga externa pode ser removida utilizando uma barra de ferro que se encaixa nos dois buracos da parte superior da manga e içando a manga fora do chão. Logo após, a abertura do piezômetro é tampada utilizando fundo de garrafa plástica para evitar a entrada de água da chuva. 


\subsection{Medição do nível do lençol freático}

Para a leitura da profundidade do lençol freático, foi utilizado o medidor de nível Solinst ${ }^{\circledR}$ (Water Level Meter), modelo 101, equipamento elétrico que possui uma fita milimetrada de $10 \mathrm{~mm}$ de largura ligada a um sensor que ao ser introduzido nos poços piezômetros emite um sinal sonoro quando encontra água, os sensores são feitos com aço inoxidável e revestidos em polietileno, oferecendo resistência e precisão, seu desenho evita aderência em superfícies molhadas (Figura 9) .

As instalações dos poços piezômetros foram feitas em setembro de 2008, e as medições ocorreram entre os dias 1 de outubro e 15 de novembro do mesmo ano. Neste período foram realizadas um total de 4 medições, com o intervalo entre elas em torno de 15 dias.

\section{Resultados e discussão}

A variação do nível do lençol freático (Tabela 1) foi considerada sob dois aspectos: 1) variação espacial, com dados indicando a dinâmica do lençol em relação à distância à margem do rio, ao longo do transecto, para cada bloco, e 2) variação sazonal, indicando a variação do nível ao longo do tempo em cada piezômetro procurando determinar sua relação com as chuvas locais.

Tabela 1: Profundidade do lençol freático do rio Gualaxo do Norte, Mariana,MG, no período observado.

\begin{tabular}{|r|r|r|r|r|r|}
\hline BLOCO & POÇOS & 04 /OUT & 18 / OUT & 01 / NOV & 15 / NOV \\
\hline 1 & 1 & 0,61 & 0,62 & 0,61 & 0,32 \\
\hline & 2 & 2,63 & 2,8 & 2,74 & 2,16 \\
\hline & 3 & abaixo $4 \mathrm{~m}$ & abaixo 4m & abaixo 4m & abaixo 4m \\
\hline 2 & 1 & 0,92 & 0,66 & 0,68 & 0,46 \\
\hline & 2 & 0,83 & 1,22 & 1,02 & 0,5 \\
\hline & 3 & abaixo $4 \mathrm{~m}$ & abaixo 4m & abaixo 4m & abaixo 4m \\
\hline 3 & 1 & 1,1 & 1,14 & 1,14 & 0,82 \\
\hline & 2 & abaixo 4m & abaixo 4m & abaixo 4m & abaixo 4m \\
\hline & 3 & abaixo 4m & abaixo 4m & abaixo 4m & abaixo 4m \\
\hline
\end{tabular}

Os resultados da variação espacial (Figura 11) apresentaram comportamentos semelhantes entre os blocos. Não foi possível acompanhar a dinâmica dos poços 3, dos blocos 1, 2 e 3 visto que nestes locais o lençol se encontra em uma profundidade maior que quatro metros e sendo o equipamento utilizado para perfurar piezômetros até os quatro metros abaixo da superfície, o mesmo ocorreu com os poços 2 do bloco 3 .

De forma geral, o lençol apresentou profundidade crescente em relação ao aumento da distância à margem do rio, isso pode ser explicado devido à área estudada apresentar relevo ondulado, possuindo altitude crescente à medida que se afasta da margem do rio. No bloco 2, tal diferença de altitude entre os poços 1 e 2 não é considerável, não havendo desta forma variações do nível do lençol pronunciáveis entre estes dois poços.

Os resultados da variação sazonal (Figura 12) apresentaram comportamentos semelhantes, com exceção do bloco 2. De forma geral, o lençol apresentou um nível constante nas três primeiras observações, possuindo uma elevação considerável do nível na observação do dia 15 de novembro. Tal comportamento pode ser explicado devido às chuvas que 
ocorreram na região (Figura 13), de setembro a novembro a pluviosidade do local aumenta, sendo as chuvas de novembro mais intensas, apresentando desta forma nível do lençol mais superficial na última observação do mês de novembro.

No bloco 2, os poços 1 e 2 apresentaram dinâmica diferente. O poço 1, que é mais próximo ao rio teve um aumento do nível do lençol em todas as observações ao passar do tempo, o mesmo não foi observado no poço 2. Como o poço 1 está mais próximo à margem do rio o nível freático deste local deve sofrer influência das chuvas que ocorrem em outros locais da bacia, enquanto o poço 2 por ser mais distante apresenta uma variação do lençol condicionada à precipitação local, o que confere ao poço 2 uma característica mais próxima ao conceito de AVA.

O estudo da variação do nível do lençol freático nos três locais estabelecidos indica que seria necessária a obtenção de mais informações sobre o local, tal como o índice topográfico, visto que o lençol tende a acompanhar o perfil topográfico do local. Além disso, é recomendável que o monitoramento do lençol freático seja realizado concomitamente com a precipitação pluviométrica para que resultados mais consistentes possam ser alcançados.

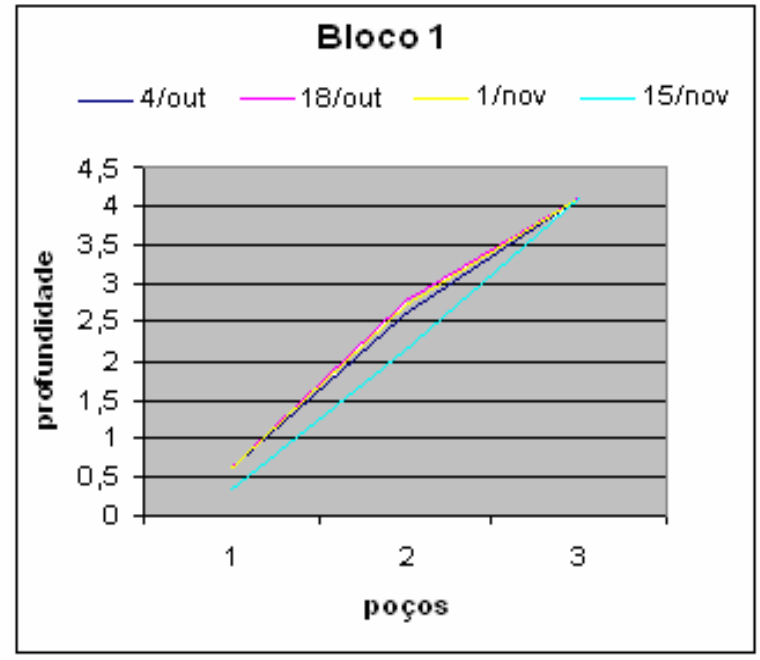

(5a)

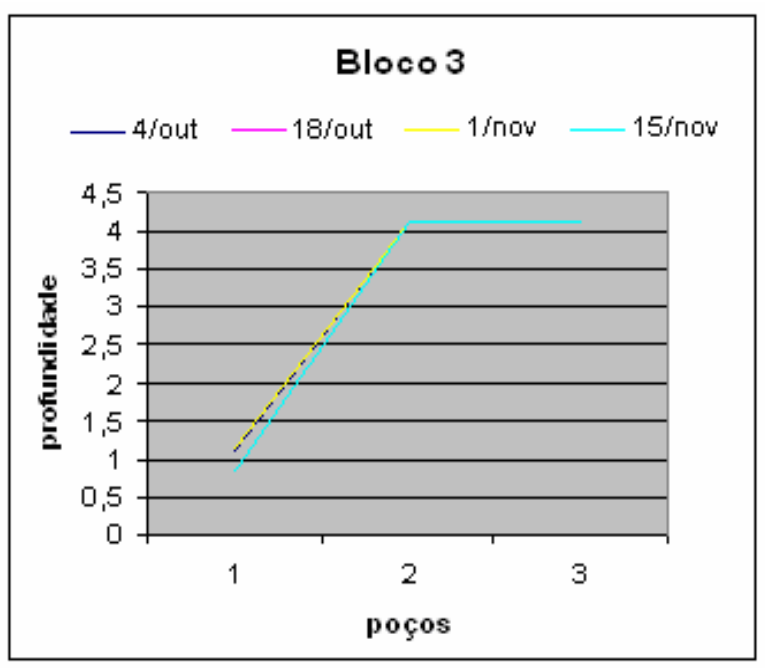

$(5 \mathrm{c})$

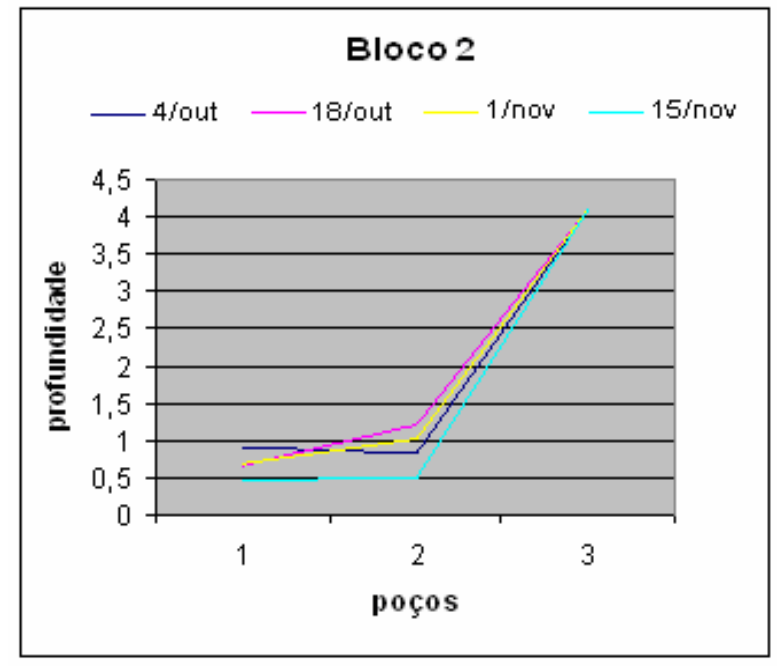

$(5 b)$

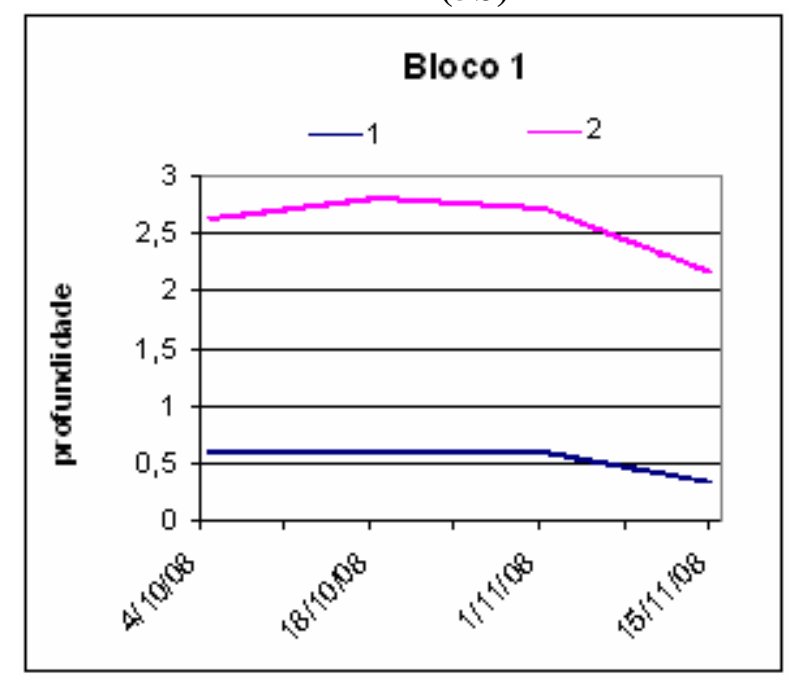

$(\mathbf{5 d})$ 


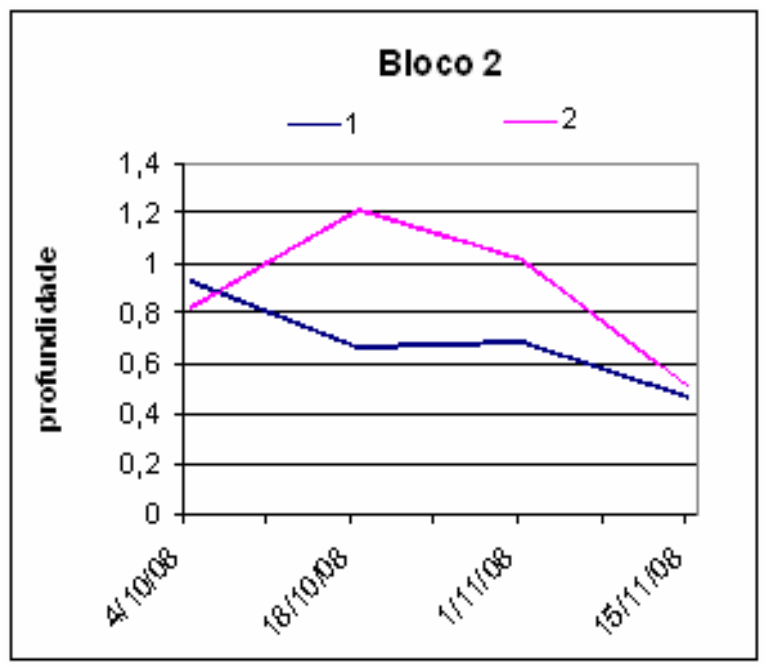

(5e)

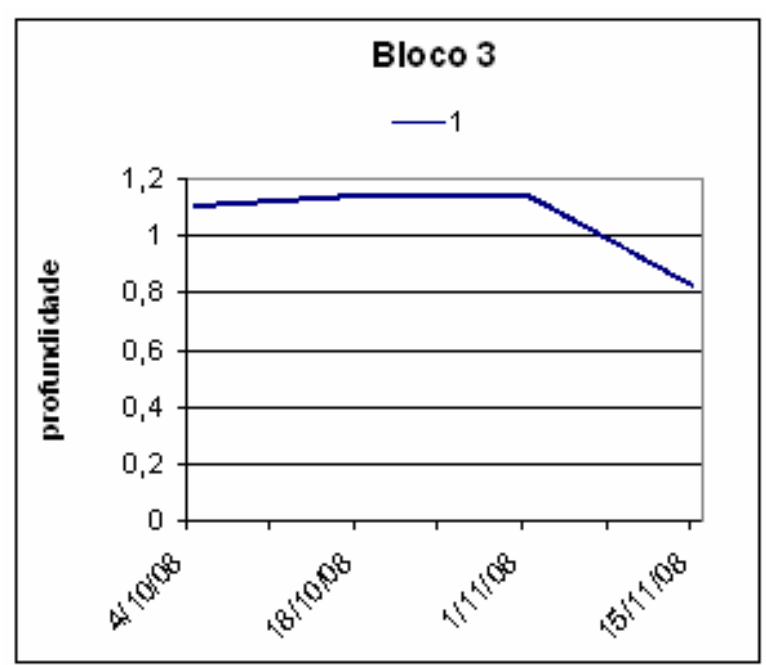

(5f)

Figura 5 a, b, c: Variação espacial da profundidade do lençol freático, em metros, nos três blocos observados seguindo uma linha perpendicular ao rio Gualaxo do Norte em MarianaMG, no período de outubro a novembro de 2008.

Figura 5 d, e, f: Variação sazonal da profundidade do lençol freático, em metros, nos três blocos observados seguindo uma linha perpendicular ao rio Gualaxo do Norte em MarianaMG, no período de outubro a novembro de 2008.

\section{Conclusão}

Apesar dos problemas constatados, a perfuração manual dos piezômetros mostrou ser uma alternativa viável para a perfuração de poços com até quatro metros de profundidade em solos argilosos.

O resultado obtido no monitoramento do nível do lençol freático indica que o lençol tende a acompanhar o relevo do terreno e a dinâmica do lençol em pontos próximos à margem do rio é diferente dos locais mais distantes.

A metodologia empregada neste trabalho, de monitorar o nível do lençol freático por meio de poços piezômetros poderia ser útil na identificação da AVA no campo.

\section{Conclusão}

Os autores agradecem à Fundação de Apóio a Pesquisa do Estado de Minas Gerais, FAPEMIG, por financiar a participação no SERHIDRO.

\section{Referências}

AMADE, P.; LIMA, H. M. Desenvolvimento Sustentável e Garimpo - O Caso do Garimpo do Engenho Podre em Mariana - Minas Gerais . In: IV Congresso Brasileiro de Mina a Céu Aberto e IV Congresso Brasileiro de Mina Subterrânea, Belo Horizonte, 2006. Anais... Belo Horizonte. 2006. Disponível em: <http://www.rem.com.br/ojs/files/files/journals/1/articles /567/ submission/review/567-2218-1-RV.doc>. Acesso em: 21 out. 2008.

ASSIS, S. V. de Evapotranspiração. In: ASSIS, S. V. de Agrometeorologia. Pelotas: Ufpel, 2002. 9p. Disponível em: < http://minerva.ufpel.edu.br/ assis/agro/agro_07. doc>. Acesso em: 16 out. 2008.

BETSON, R. P. What is watershed runoff? Journal of Geophysical Research, v. 69, p. 1541, 1964. 
BEVEN, K. J.; KIRKBY, M. J. A physically based, variable contributing area model of basin hydrology. Hydrological Sciences Bulletin, v.24, p.43-69, 1979. Disponível em: <www.itia.ntua.gr/hsj/24/hysj_24_01_0043.pdf>. Acesso em: 15 out. 2008.

BOHN, C. C. Guide for fabricating and installing shallow ground water observation Wells. Research Note RMRS- RN 9, USDA Forest Service, Rocky Mountain Research Station. 2001, 5p. Disponível em: < http://www.fs.fed.us /rm /pubs /rmrs_rn009.pdf>. Acesso em: 23 out. 2008.

CEDERSTROM, D. J. Água Subterrânea: uma introdução. Rio de Janeiro: USAID, 1964. 280 pg.

CRUCIANI, D. E. A drenagem na agricultura. 1. ed. São Paulo: Livraria Nobel S.A., 1980. 333p.

DIAS, H. C. T. A importância do MBH para o setor florestal. In: Seminário sobre manejo integrado de bacias hidrográficas em florestas plantadas. Anais... UFV. Viçosa, 2007. Disponível em: < http://www.sif.org.br/files/a_importancia_do_mbh_para_o_setor_florestal.pdf>. Acesso em: 15 out. 2008.

HORTON, R. E. An approach toward a physical interpretation of infiltration capacity. Soil Science Society of America Proceedings. v. 4, p. 399-417, 1940.

LIMA, W. P. Regime da água do solo em microbacias florestadas. In: LIMA, W. P. Introdução ao manejo de bacias hidrográficas. Piracicaba: Esalq, 2006. cap. 6, p. 93-131.Anais... Piracicaba, 2006. Disponível em: < http://www.esalq.usp.br/departamentos/lcf/lab/lhf/arquivos /CAPITULO\%206.pdf>. Acesso em: 16 out. 2008.

LIMA, W. P.; ZAKIA, M. J. B. Hidrologia de matas ciliares. In: RODRIGUES, R. R,; LEITÃO FILHO, H. F. Matas ciliares: conservação e recuperação. São Paulo: EDUSP/ FAPESP, 2000. cap. 3, p. 33 - 44.

MOLCHANOV, A. A. Hidrologia Florestal. Tradução de Zózimo Pimenta de Castro Rego. Lisboa: Fundação Calouste Gulbenkian, 1963. 419 p.

TODD, D. K. Hidrologia de águas subterrâneas. Rio de Janeiro: USAID, 1967 